(c) American Dairy Science Association, 2007.

\title{
Prevalence and Risk Factors for Postpartum Anovulatory Condition in Dairy Cows
}

\author{
R. B. Walsh, ${ }^{* 1}$ D. F. Kelton, ${ }^{\star}$ T. F. Duffield, ${ }^{\star}$ K. E. Leslie, ${ }^{*}$ J. S. Walton, $\dagger$ and S. J. LeBlanc ${ }^{\star}$ \\ *Department of Population Medicine, and \\ †Department of Animal and Poultry Science, University of Guelph, Guelph, Ontario, Canada, N1G 2W1
}

\begin{abstract}
The objectives of this research were to determine the prevalence of the anovulatory condition within a temperate region of North America and identify cow-level and herd-level risk factors for this condition. A total of 1,341 cows from 18 herds were classified as cycling or anovular based on skim milk progesterone concentration determined at 46 and $60 \pm 7 \mathrm{~d}$ in milk. Calving history, periparturient disease incidence, body condition score, milk ketone concentration in the first $2 \mathrm{wk}$ of lactation, and first 305-d mature-equivalent milk projections were recorded. Reproductive and culling information was retrieved monthly from the Dairy Herd Improvement Association. The cow-level prevalence of anovulation was $19.5 \%$, with a herd-specific range from 5 to $45 \%$. Accounting for the effect of clustering at the herd level, cows experiencing a difficult calving, cows with twin calvings, displaced abomasum, and cows with subclinical ketosis in the first week after calving were at greater risk for diagnosis of anovulation. Anovular cows within herds using ovulation synchronization programs were inseminated at the same time postpartum with a 6-percentage point reduction in the probability of pregnancy relative to cycling herdmates (29.7 vs. $35.9 \%$, respectively), whereas anovular cows in herds breeding based on observed estrus were inseminated 8 $\mathrm{d}$ later and suffered a 10-percentage point reduction in the probability of pregnancy at first insemination (20.3 vs. 30.5). Time to pregnancy was delayed in anovular cows by $30 \mathrm{~d}$ (156 vs. $126 \mathrm{~d}$ ). Using survival analysis, the impact of anovulation decreased with time. The daily probability of pregnancy (hazard ratio) was similar to cycling cows by $165 \mathrm{~d}$ in milk. The results underline the important associations of peripartum health with reproductive function and performance.
\end{abstract}

Key words: anovulation, time to pregnancy, ketosis, progesterone

Received June 6, 2006.

Accepted July 31, 2006.

${ }^{1}$ Corresponding author: rwalsh@uoguelph.ca

\section{INTRODUCTION}

Establishment of a predictable estrus cycle before the end of the voluntary waiting period is strongly associated with increased probability of pregnancy at first insemination and reduced time to pregnancy (Thatcher and Wilcox, 1973; Shrestha et al., 2004b). Cows not observed in estrus during the voluntary waiting period have a significantly higher culling risk than cows that have displayed estrus (Thatcher and Wilcox, 1973). Independent of milk production, there is a significant economic benefit in increasing the probability of pregnancy at first insemination and reducing the time to pregnancy (Meadows et al., 2005).

Following calving there is a normal period of anestrus during which uterine involution occurs. Thereafter, coordinated activity of the hypothalamic-pituitary axis and ovaries reestablishes, culminating in ovulation and reinitiation of a regular cycle of estrus and ovulation (Wiltbank et al., 2002). Recent research has suggested that approximately $20 \%$ of dairy cows have neither displayed estrus nor ovulated before the start of the breeding period (Opsomer et al., 2000; Moreira et al., 2001). Ovulation synchronization protocols permit tighter control of time to first service; however, the probability of pregnancy in cows failing to return to a predictable ovulatory cycle is significantly reduced (Gumen et al., 2003).

There are many factors that influence time to first ovulation, and whether normal estrus and ovulatory cycles are maintained thereafter, including breed, parity, season, BCS, peripartum disease, and a variety of nutritional effects. Attention has focused on the association between postpartum negative energy balance and the resumption of cyclicity in dairy cows (Butler, 2000). Some studies were conducted in one herd at a time, in a single season, or have focused on characterization of the return to ovulatory cycles rather than identification of potential risk factors (Lamming and Darwash, 1998). The objectives of the current study were to estimate the cow-level prevalence of anovulatory condition in Ontario dairy herds, and identify potential herd- and cow-level risk factors for the condition. 


\section{MATERIALS AND METHODS}

A convenience sample of 20 dairy herds located in Ontario, Canada, collaborated in the study. The study population consisted of lactating dairy cows in typical commercial dairy herds housed in free-stall $(n=10)$ and tie-stall $(\mathrm{n}=10)$ barns. Herd size ranged from 30 to 320 milking cows. Herd inclusion was dependent on regularly scheduled herd visits conducted by a collaborating veterinarian, willingness to implement a ketonemonitoring program for the duration of the study, exclusive use of $\mathrm{AI}$ in the milking herd, and participation in a milk-recording program through Canwest DHI. Producers implementing ovulation synchronization protocols $(n=6)$ for first insemination, with $(n=2)$ or without $(\mathrm{n}=4)$ presynchronization with 2 doses of $\mathrm{PGF}_{2 \alpha}$, agreed to enroll eligible cohorts of cows at the scheduled herd visit and take milk samples on the day of $\mathrm{PGF}_{2 \alpha}$ injection, but before the scheduled $\mathrm{PGF}_{2 \alpha}$ was administered.

Cows and heifers were assigned a BCS using a 5point scale (Ferguson et al., 1994) in the 2 wk before calving and again between 52 and 66 DIM. Analysis was performed using BCS as an indicator variable, such that cows were classified as thin $(\leq 2.5)$, normal $(\geq 2.75$ to $\leq 3.5)$ or fat $(\geq 3.75)$ at each of the 2 sampling periods. To account for differences in BCS classification between veterinarians, the change in BCS rather than the absolute BCS value was offered as a covariate associated with identification as anovulatory (Hady et al., 1994). Loss of greater than 1 BCS unit in early lactation was used to identify animals that suffer from severe negative energy balance (Loeffler et al., 1999). Parity and calving date were recorded. Calving date was subsequently classified into season of calving (fall = September through November; winter = December through February; spring = March through May; summer = June through August). The occurrence of dystocia (hard pull or veterinary-assisted calvings), twins, retained placenta (failure to pass fetal membranes by $24 \mathrm{~h}$ after parturition), and milk fever (cow down $<24 \mathrm{~h}$ after calving with no other illness) were recorded within $24 \mathrm{~h}$ of parturition. Milk BHBA concentration was determined using a previously validated milk test (KetoTest; Elanco Animal Health; Guelph, ON; Geishauser et al., 2000) between the second and eighth day postcalving and again $7 \mathrm{~d}$ later. Additional health records were maintained using a combination of on-farm paper and computer-based recording systems. Recorded disease events included metritis (severe infection of the uterus, cow off feed with a fever $>39.5^{\circ} \mathrm{C}$, and foul-smelling uterine discharge), clinical ketosis (off feed and milk BHBA concentration $>500 \mu \mathrm{mol} / \mathrm{L}$ ), displaced abomasum (diagnosed by the farm veterinarian), and clinical mastitis (visibly abnormal milk). Recent studies (Garbarino et al., 2004; Hernandez et al., 2005) indicated that moderate to severe lameness was associated with commencement of ovarian function and reproductive performance. Therefore, when cows were restrained for collection of milk samples, cows with an arched back while standing (corresponding to moderate to severe lameness; i.e., score 3 or 4 from Sprecher et al., 1997) were classified as lame, and cows without a back arch while standing were classified as nonlame. Skim milk progesterone concentrations were measured twice, 14 d apart (range 10 to 16), with the first sample taken between 37 and 51 DIM and the second sample between 52 and 66 DIM. Milk samples (approximately $40 \mathrm{~mL}$ ) were collected by forestripping at the morning milking into vials containing a bacteriocidal tablet $(6 \mathrm{mg}$ of 2 bromo-2-nitropropane-1,3-diol and $0.3 \mathrm{mg}$ of pimaricin). Samples were accumulated at the respective veterinary clinic and stored at $4^{\circ} \mathrm{C}$. Milk samples were shipped to the University of Guelph between Monday and Wednesday each week to ensure samples were received within the same week. After receipt, whole milk was stored at $4^{\circ} \mathrm{C}$ until aspiration of the fat layer. A $2-\mathrm{mL}$ sample of skim milk was stored at $-20^{\circ} \mathrm{C}$ until progesterone concentrations were determined using a previously validated solid-phase RIA procedure (Gowan and Etches, 1979) and the Coat-a-Count system (Diagnostic Products Corporation, Los Angeles, CA). Animals were classified as anovulatory if the progesterone concentration was less than $1 \mathrm{ng} / \mathrm{mL}$ in both skim milk samples. The limit of detection of the progesterone assay was 0.12 $\mathrm{ng} / \mathrm{mL}$, and the inter- and intraassay coefficients of variation were 18.2 and $3.9 \%$, respectively.

Reproductive records including insemination, pregnancy, and culling dates were retrieved from electronic files maintained by producers and Canwest DHIA every month. Herd file backups were obtained and stored permanently at 6-mo intervals to ensure access to all individual cow data. Pregnancy diagnosis was performed at 2 -wk herd visits with the earliest time for insemination to pregnancy exam being $28 \mathrm{~d}$, but the majority performed at $35 \mathrm{~d}$ or later. Pregnancy loss was identified at routine reconfirmation or if a cow was recorded as pregnant to an insemination performed after a previous diagnosis of pregnancy. A herd questionnaire was administered within 6 mo of herd enrollment to encourage accurate data recording, reconfirm the experimental protocol, and evaluate the impact of herd management on their respective performance. The questionnaire focused on cow management through the dry period up to and including the time of first insemination. Milking frequency ( 2 vs. 3 times/d), use of ovulation synchronization protocols for first insemination $(>90 \%$ of the herd 
vs. $<50 \%$ ), hoof-trimming frequency, and footbath protocols were recorded.

General information including barn type (free-stall vs. tie-stall), stall dimensions (width and length), stall surface (pasture mat, concrete, or sand), and bedding material (sand, shavings, or straw), and the number of stall rows were recorded. Alley surface (rubber vs. smooth or ridged concrete) was recorded. Heat-abatement strategies were recorded for each herd without attempting to track variation in ambient temperatures experienced by individual herds.

Data were recorded concerning the feeding program used, the number of ration changes occurring between dry-off and 60 DIM, and any differences in management between primiparous and multiparous animals. The frequency of ration evaluation, forage DM determination, and number of times feed was delivered per day were recorded. Additionally, linear bunk space and water space per stall were measured. These variables were recorded for both the milking herd and dry cows.

\section{Data Management and Statistical Analysis}

All analyses were performed using Intercooled STATA 9.1 (STATA Corporation LP, 2005). Sample size estimates based on an estimated prevalence of anovulatory condition of $20 \%$, an allowable error of $5 \%$ in the estimated prevalence, and cluster sampling suggested that a minimum of 750 cows were needed (Dohoo et al., 2003). Descriptive statistics were used to determine if cows that completed the sampling protocol differed from those cows calving over the study period that failed to complete the protocol. For animals from which 2 milk samples were collected, the time between the second milk sample and insemination was evaluated to estimate the potential for misclassification of anovulation (i.e., low progesterone associated with estrus resulting in false classification as anovulatory of animals that began to cycle between samples). Low progesterone $(<1$ $\mathrm{ng} / \mathrm{mL}$ ) in both milk samples was the definition of anovulation; as such, cows inseminated within $5 \mathrm{~d}$ of the second milk sample were classified as anovulatory. In addition, milk collection dates were cross-referenced with reproductive hormone injections to avoid confounding of progesterone if prostaglandin was given (in deviation from the protocol) within $10 \mathrm{~d}$ of the milk collection date.

Distributions of specific variables were evaluated among animals that were classified as anestrus and those that were cycling. Accounting for correlation of cows within herds, the season of calving and parity (potential risk factors for anovulation) were evaluated one at a time. Continuous independent variables were offered to a multivariable logistic regression model un- adjusted to assess their linear relationship. In instances where the linearity assumption was violated, these variables were evaluated using multiple linear relationships (splines) or were transformed into categorical variables. Risk factors that had univariate associations $(P<0.10)$ were subsequently evaluated through a backward stepwise multivariable logistic regression model using a generalized estimating equation to account for correlation of cows within herds. Variables were removed from the model if the associated $P>0.10$, and potential 2-way interactions were evaluated if both main effects were significant.

Time from calving to first insemination and to pregnancy was estimated using a Kaplan-Meier life-table to account for enrolled cows that were not inseminated or not diagnosed pregnant before the end of the study. Kaplan-Meier (product limit) survival function estimates were used to calculate crude associations of anovulation with median time from calving to first insemination and median time to pregnancy, as well as to generate a graph of cumulative pregnancy risk over time. The restricted median time to event and 95\% confidence intervals were determined as the first time the survival function was less than or equal to 0.50. The effect of anovulation on time to pregnancy was analyzed using multivariable survival analysis using Cox's proportional hazards regression. The Cox proportional hazard model measures the probability of pregnancy per unit time expressed as a hazard ratio. Robust standard errors were generated to account for clustering.

The main effect of interest was the impact of anovulation on time to first insemination and pregnancy. In addition to the main effect of cyclic status, the effects of parity, season of calving, periparturient disease, and milk BHBA concentration in each week postpartum were offered to the model as covariates. Estimation of the effect of cyclic status on time to first insemination was evaluated separately in herds systematically using an ovulation synchronization protocol and timed AI for first service. These models were built by manual backward stepwise elimination, removing the covariate with the largest probability value at each step, until all covariates were significant at $P<0.10$. If 1 level of a categorical variable was significant, all levels were retained. Significant differences between class variables were assessed using a Wald postestimation test. Twoway interactions were assessed among significant variables by generating a cross product term. If the interaction term was significant at $P \leq 0.05$, both fixed effects and the interaction term were retained in the model. The assumption of proportional hazard over time was assessed graphically using log-log plots. Violations of the proportional hazard assumption were corrected by 
allowing the covariate to vary with the log of time (Dohoo et al., 2003). This correction retains the standard hazard rate interpretation; however, it requires the calculation of the hazard rate at specific points in time.

Herd-level risk factors were investigated modeling the herd-specific seasonal prevalence of anestrus. Season was dichotomized into fall vs. all other seasons. This was done to account for different prevalence of anovulation in fall-calving cows. In addition, this division separated cows that had a dry period on pasture and captured a period with an increased number of calvings. Linear regression was used, accounting for the effect of clustering at the herd level. Herd size, barn design (free-stall vs. other), number of rows, stall design [large $(>127 \mathrm{~cm}$ wide and $>183 \mathrm{~cm}$ long) vs. small], linear feedbunk space per stall in the milking herd and dry groups, seasonal pasture use for the milking herd and dry cows, lameness prevention strategies, heatabatement strategies, nutritional evaluation frequencies, feed delivery frequency, number of ration changes from dry-off to 60 DIM, milking frequency, and use of ovulation synchronization protocols were considered as covariates. Herd performance variables including proportion of cows culled before $60 \mathrm{DIM}$ and herd prevalence of subclinical ketosis were evaluated in the first and second weeks.

\section{RESULTS}

Twenty herds were enrolled in the study from January 2003 until April 2005. One herd withdrew within 3 mo of enrollment, and a second herd was excluded for failure to comply with the sampling protocol. A total of 2,645 cows calved in the remaining 18 herds during the study (herd participation ranged 7 to $15 \mathrm{mo}$ ). From this population 277 (10.5\%) were culled before 52 DIM, excluding them from possible enrollment. A total of $1,575(66.5 \%)$ animals had 2 milk samples collected. Animals were excluded if the milk samples were collected outside of the sampling window or if an animal received an injection of prostaglandin within $10 \mathrm{~d}$ before either milk sample. A total of 1,341 (56.7\%) cows met all inclusion criteria. Within each herd, the proportion of calvings that met the study inclusion criteria ( 2 milk samples collected 10 to $16 \mathrm{~d}$ apart) ranged from 33 to $90 \%$ of calvings (median $63 \%$ ).

Of the 18 herds included in the analysis, 5 reported no use of timed AI (TAI) protocols (31\% of cows), 7 herds applied a TAI protocol to animals failing to display estrus by a herd-specific time postpartum (47\% of cows), and the remaining 6 herds reported application of a TAI protocol for greater than $90 \%$ of animals at first AI ( $21 \%$ of cows). For analysis of time to first insemination, herds using observed estrus and occasional use of TAI protocols were combined and compared with herds enrolling $>90 \%$ of cows into an ovulation synchronization and TAI program.

A total of 266 animals were inseminated before the second milk sample being collected. Nine percent of these (24/266) were classified as anestrous based on milk progesterone concentrations. Of the apparently noncycling cows, 75\% (18/24) were from herds that used estrus detection to identify cows for first insemination. Fifteen apparently noncycling cows (progesterone $<1$ $\mathrm{ng} / \mathrm{mL}$ in both milk samples) were excluded from the analysis because of hormonal therapy within $10 \mathrm{~d}$ before a milk sample.

Forty-three percent of cows had circulating progesterone concentrations $<1 \mathrm{ng} / \mathrm{mL}$ at the first milk sample. At the second milk sample $37 \%$ of cows had circulating progesterone concentrations less than $1 \mathrm{ng} / \mathrm{mL}$. The overall prevalence of anovulation was 19.5\% [95\% confidence interval (CI): 17.4 to 21.7\%]. A large amount of herd-level variation was evident [5\% (95\% CI: 1.0 to $13.7 \%$ ) to $44.1 \%$ (95\% CI: 33.2 to $55.3 \%$ ); Figure 1 ).

The parity distribution (first lactation: $33 \%$; second: $33 \%$; $\geq$ third: $33 \% ; P=0.47$ ) and previous days dry (mean multiparous animals only $=74.1 ; 95 \%$ CI: 71.0 to 79.2 ; $P=0.58$ ) of animals meeting the inclusion criteria relative to animals lost to follow up was not different. Periparturient disease information was more likely to be recorded in animals that met all inclusion criteria than in animals that did not. The culling pattern was weighted earlier in lactation for cows that did not have 2 milk samples collected relative to cows that met all inclusion criteria.

In the population of animals available for analysis, $8.4 \%$ of calvings were classified as a hard pull or required veterinary assistance. There were $49(3.6 \%)$ twin calvings. Periparturient diseases included milk fever (2.4\% among lactation $\geq 2)$, retained placenta $(8.8 \%)$, metritis $(7.9 \%)$, clinical ketosis $(3.1 \%)$, and displaced abomasum (3.1\%). Before 60 DIM, $8.9 \%$ of animals had a clinical case of mastitis and a lameness event was reported in $6.5 \%$ of cows.

Milk BHBA concentrations were determined in each of the first and second weeks postpartum in 1,041 animals. Twenty-six percent of animals ( $\mathrm{n}=1,041 ; 95 \%$ CI: 23.6 to 29.1) were subclinically ketotic (SCK; milk BHBA $\geq 100 \mu \mathrm{mol} / \mathrm{L}$; Geishauser et al., 2000) in the first week postpartum. There was large variation in prevalence between herds (5.1 to 82.3\%). In the second week postpartum $25.5 \%$ (95\% CI: 22.8 to 28.2 ) of animals were SCK with equally large variation between herds (5.5 to $84.6 \%$ ).

Cows experiencing dystocia or calving with twins were significantly more likely to be classified as anovulatory in a model accounting for clustering of cows 


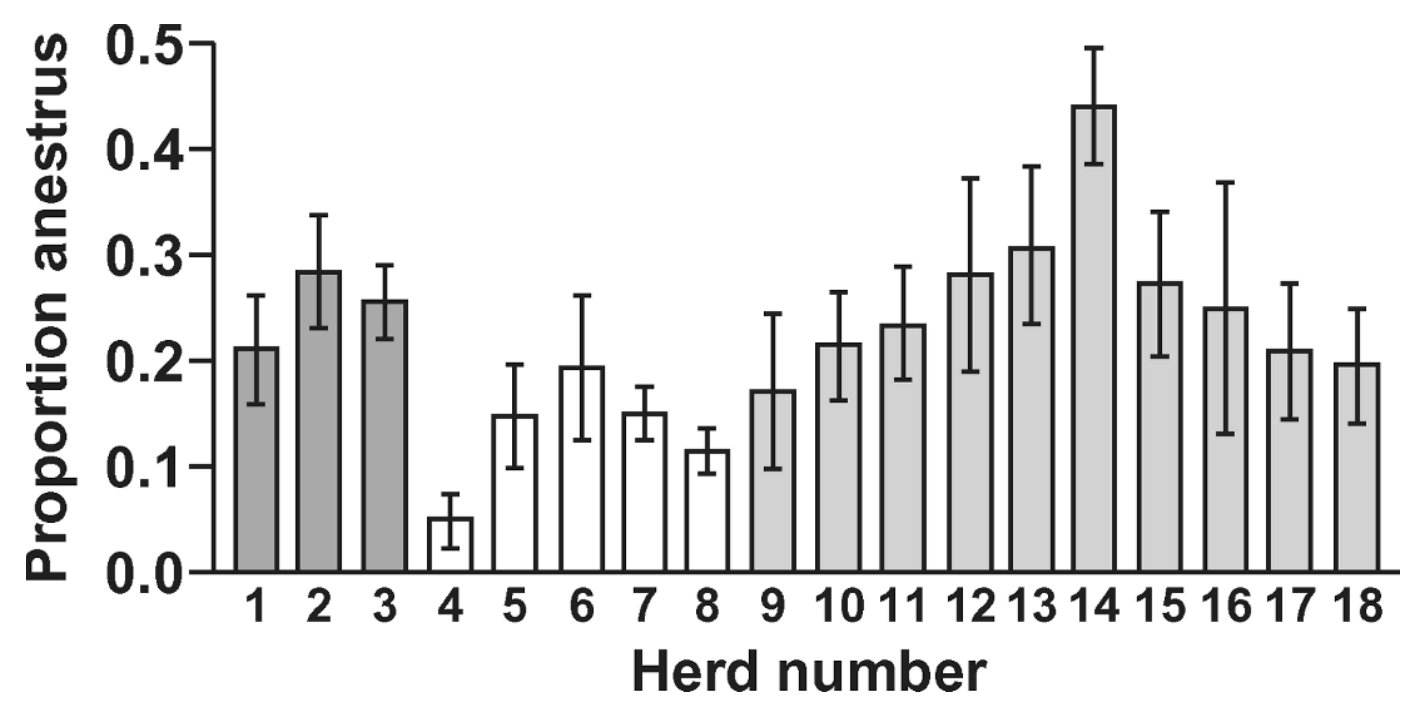

Figure 1. The prevalence of anovulation (mean $\pm \mathrm{SE}$ ), defined as skim milk progesterone concentrations $<1 \mathrm{ng} / \mathrm{mL}$ determined at 46 and $60 \pm 7$ DIM in 18 Ontario dairy herds between January 2004 and April 2005. Herd numbers 1 to 3 were in 3-row free-stall barns, herds 4 to 8 were in 2 -row free-stall barns, and herds 9 to 18 were in tie-stall barns.

within herd, season of calving, and parity, and in a multivariable logistic regression model including all significant factors. Similarly, retained placenta and displaced abomasum were significantly associated with anovulation, whereas lameness significantly increased the risk of anovulation when accounting for the effects of parity, season, and herd (Table 1). Anovular cows were significantly more likely to be SCK in both the first and second week. But, after accounting for the effect of periparturient disease and milk production, animals with milk BHBA $\geq 100 \mu \mathrm{mol} / \mathrm{L}$ between 2 and 8 DIM were 1.5 times more likely classified as anovular. The probability of anovulation decreased by $2 \%$ for every $100-\mathrm{kg}$ increase in the first $305-\mathrm{d}$, mature-equivalent milk projection between 5,000 and $9,500 \mathrm{~kg}$. The risk of anovulation (17.2\%, 95\% CI: 14.5 to 19.8$) \mathrm{did}$ not change as first 305-d, mature-equivalent milk projection increased above $9,500 \mathrm{~kg}$. The prevalence of anovulation changed with season. Animals calving in the fall were $46 \%$ less likely to be anovular than cows calving in the winter, whereas animals calving in the spring were significantly more likely to be anovulatory relative to animals calving in the fall. Cows calving in the summer were at an intermediate risk of anovulation between cows calving in the fall and those calving in the spring (Table 1). Days dry, the fat to protein ratio at first DHIA milk test, BCS at calving, BCS at 60 DIM, and the change in BCS were not significantly associated with the risk of being classified as anovular.

Multiparous cows and cows with a retained placenta were inseminated later than primiparous animals and animals that did not have a retained placenta account- ing for the effect of clustering at the herd level. First insemination in anovular cows occurred $8 \mathrm{~d}$ later relative to cycling cows in herds not using TAI programs in all animals (Table 2). A total of 23 anovular animals were inseminated before their second milk sample, and 223 cycling animals were inseminated before their second milk sample. Two-thirds of cows inseminated before the second milk sample were from herds inseminating animals based on observed estrus. The probability of pregnancy at first service in cows that were inseminated before the second milk sample was $8.7 \%(2 / 23)$ and $25.5 \%$ (57/223) in anovular and cycling cows, respectively.

Accounting for parity and the effect of clustering at the herd level, anovular cows inseminated at observed estrus were $55 \%$ less likely (OR $=0.45 ; P=0.006$ ) to conceive at first insemination relative to cycling cows bred in a TAI program (Table 3). Anovulatory cows bred in a TAI program and cycling cows bred at observed estrus were not significantly different from TAI cycling cows.

Time to pregnancy in anovulatory animals was delayed by $30 \mathrm{~d}$ relative to cycling animals (median 156 vs. $126 \mathrm{~d}$; Table 4 and Figure 2). Multiparous animals $(P<0.001)$ and animals with a retained placenta $(P=$ 0.006 ) became pregnant more slowly than did primiparous animals and animals without retained placenta. There were no significant 2 -way interactions in this model. The daily probability of pregnancy in anovulatory cows increased over time, such that anovular and cyclic cows had the same probability of pregnancy at 165 DIM (Table 4). The risk of pregnancy loss (based on 
Table 1. Odds ratio and 95\% confidence intervals (CI) for significant factors affecting classification of anovulatory condition based on 2 skim milk progesterone determinations at 46 and $60 \pm 7$ DIM

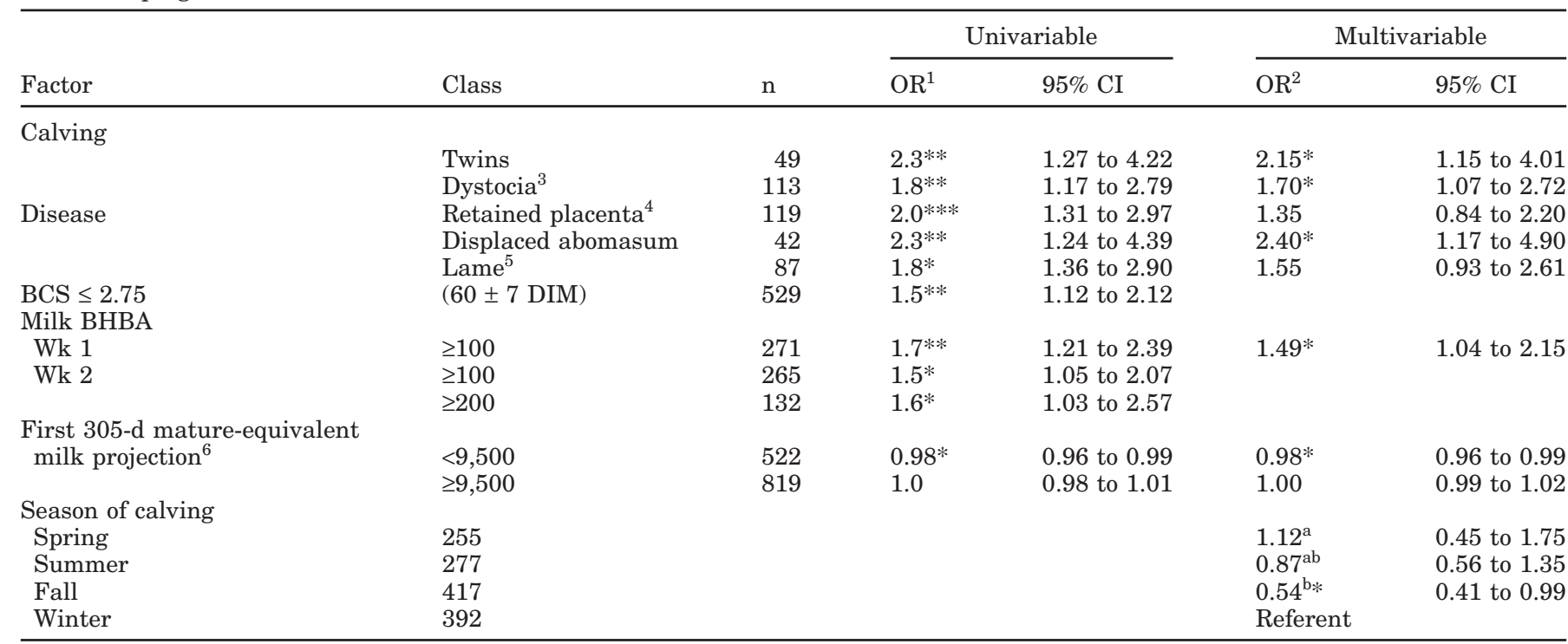

${ }^{\mathrm{a}, \mathrm{b}}$ Pairwise comparison different letters represent significant difference $(P<0.05)$.

${ }^{1}$ Odds ratio; herd, parity, and season of calving in all models, other factors in the column modeled individually in each model.

${ }^{2}$ Odds ratio; multivariable model including all variables in the column and accounting for the impact of clustering at the herd level.

${ }^{3}$ Dystocia, including hard pull and calvings requiring veterinary assistance.

${ }^{4}$ Retained fetal membranes $24 \mathrm{~h}$ after calving.

${ }^{5}$ Lameness in first 66 DIM scored at $60 \pm 7$ DIM.

${ }^{6}$ Per 100-kg increase in DHIA first 305-d mature-equivalent milk. Projection modeled as a linear relationship below and above the cutpoint. $* P<0.05 ; * * P<0.01 ; * * * P<0.001$

diagnosis of nonpregnancy at pregnancy reconfirmation or a diagnosis of pregnancy to an insemination occurring subsequent to a previous diagnosis of pregnancy) was not different between cycling $(6 \%, 66 / 1,079)$ and anovular $(5 \%, 13 / 262)$ cows.
The herd-level prevalence of anovulation was analyzed for herd-level risk factors using the seasonal prevalence of anovulation as a continuous outcome. A total of 34 herd-seasons were available for analysis; 2 herdseasons were excluded because less than $10 \%$ of poten-

Table 2. Final Cox proportional hazard model for time to first insemination of 1,341 lactating dairy cows from 18 Ontario dairy herds classified as cycling or anovulatory based on progesterone measured in 2 skim milk samples taken at 46 and $60 \pm 7$ DIM

\begin{tabular}{lllllll}
\hline $\begin{array}{l}\text { Herd reproduction } \\
\text { program }\end{array}$ & Factor & $\mathrm{n}$ & $\mathrm{AI}^{1}$ & $\begin{array}{l}\text { Hazard } \\
\text { ratio }\end{array}$ & $P$ & $95 \%$ CI \\
\hline $\mathrm{HD}^{\circ}<50 \% \mathrm{OVS}^{2}$ & Anestrus & 182 & $80^{\mathrm{b}}$ & 1.22 & 0.37 & 0.8 to 1.9 \\
& Cycling & 862 & $72^{\mathrm{a}}$ & 1.80 & 0.01 & 1.1 to 2.7 \\
& Anestrus & 80 & $78^{\mathrm{ab}}$ & 1.16 & 0.16 & 0.9 to 1.4 \\
& Cycling & 217 & $76^{\mathrm{b}}$ & Referent & & \\
& Multiparous & 912 & & 0.84 & 0.04 & 0.7 to 0.9 \\
& Primiparous & 429 & & Referent & & \\
& Retained placenta & 119 & & 0.75 & $<0.001$ & 0.6 to 0.8 \\
\hline
\end{tabular}

\footnotetext{
${ }^{\mathrm{a}, \mathrm{b}}$ Different letters within column represent a significant difference based on a Wald postestimation test $(P<0.001)$.

${ }^{1}$ Kaplan-Meier estimate of time from device insertion to first insemination. This method takes into account all animals, including animals culled before confirmed pregnancy. The time to first insemination estimate represents the values associated with the first time the survival probability stabilized below $50 \%$.

${ }^{2}$ Heat detection (HD) or $<50 \%$ of first insemination performed after an ovulation synchronization (OVS) protocol and timed AI.

${ }^{3}$ More than $90 \%$ of cows subjected to timed AI after an ovulation synchronization protocol (OVS).
} 
Table 3. Multivariable logistic regression of the probability of pregnancy at first service for 1,227 lactating dairy cows from 18 Ontario dairy herds classified as cycling or anovular based on progesterone measured in 2 skim milk samples taken at 46 and $60 \pm 7$ DIM

\begin{tabular}{lllllll}
\hline $\begin{array}{l}\text { Herd reproduction } \\
\text { program }\end{array}$ & Factor & $\mathrm{n}$ & FSCR $^{1}$ & $\begin{array}{l}\text { Odds } \\
\text { ratio }\end{array}$ & $P$ & $95 \%$ CI \\
\hline $\mathrm{HD}$ or $<50 \% \mathrm{OVS}^{2}$ & Anovular & 162 & $20.3^{\mathrm{b}}$ & 0.45 & 0.006 & 0.26 to 0.79 \\
& Cycling & 810 & $30.5^{\mathrm{a}}$ & 0.80 & 0.3 & 0.52 to 1.22 \\
& Anovular & 74 & $29.7^{\mathrm{ab}}$ & 0.67 & 0.19 & 0.10 to 1.22 \\
& Cycling & 181 & $35.9^{\mathrm{a}}$ & Referent & & \\
& Multiparous & 823 & & 0.73 & 0.02 & 0.57 to 0.95 \\
& Primiparous & 404 & & Referent & & \\
\hline
\end{tabular}

${ }^{a, b}$ Values within a column with different superscript letter indicate odds ratios significantly different from each other.

${ }^{1}$ Probability of pregnancy at first insemination.

${ }^{2}$ Heat detection (HD) or $<50 \%$ of first insemination performed after an ovulation synchronization (OVS) protocol and timed AI.

${ }^{3}$ More than $90 \%$ of cows subjected to timed AI after an ovulation synchronization protocol (OVS).

tial calvings were captured. The covariates included in the model had a high degree of collinearity. All herds were fed a TMR, and all herds included rumensin in the ration. All tie-stall herds had wide stalls $(>127 \mathrm{~cm})$, whereas all free-stall herds had narrow stalls. Linear feedbunk space per stall exceeded the standard recommendation of $53.4 \mathrm{~cm}$ in all management groups except free-stall barns with 3- or 6-row configurations. Accounting for the effect of clustering at the herd level, the prevalence of anovulation was decreased by $11 \%$ $(P=0.007)$ and $7.2 \%(P=0.10)$ in 2 -row and 3-row freestall barns relative to tie-stall barns (Figure 1).

The herd prevalence of anovulation increased by $2.1 \%$ for every $10 \%$ increase in the herd prevalence of SCK in the first week postpartum. The prevalence of SCK was $15.4,38.6$, and $29.8 \%$ in 2-row free-stalls, 3-row free-stalls, and tie-stalls, respectively. The proportion of cows culled before $50 \mathrm{DIM}$, the use of pasture during the summer, and all possible 2-way interactions were not significant. Residual analysis identified one leverage herd. Exclusion of this herd did not alter the coefficient estimates but it did alter the significance of the Wald test for ketosis in the first week.

\section{DISCUSSION}

The unique feature of this epidemiological study was the inclusion of multiple herds of varying size and management. The use of 2 milk samples collected 10 to 16 d apart is capable of detecting luteal activity, without discrimination of normal and abnormal progesterone profiles (Lamming and Darwash, 1998). Observational studies are powerful tools for screening large numbers of potential risk factors. The prospective nature of this study permitted investigation of the temporal ordering of events, but not necessarily identification of the causal mechanisms. In addition, field studies may suffer from failure of compliance with the study protocol. The current project attempted to mitigate compliance issues through a direct-to-producer incentive program for each cow that met all inclusion criteria, and 3 herd-specific updates during the trial period. An average of 56\% of animals that stayed in the milking herd beyond 52 DIM met all inclusion criteria. This was below our goal of $70 \%$ of cows; however, the cows used in the analysis were representative of those eligible for inclusion in the study.

Table 4. Final Cox proportional hazard model for the time to pregnancy of lactating dairy cows from 18 Ontario, Canada dairy farms classified as cycling or anovular based on progesterone determined at 2 skim milk samples taken around 46 and $60 \pm 7$ DIM

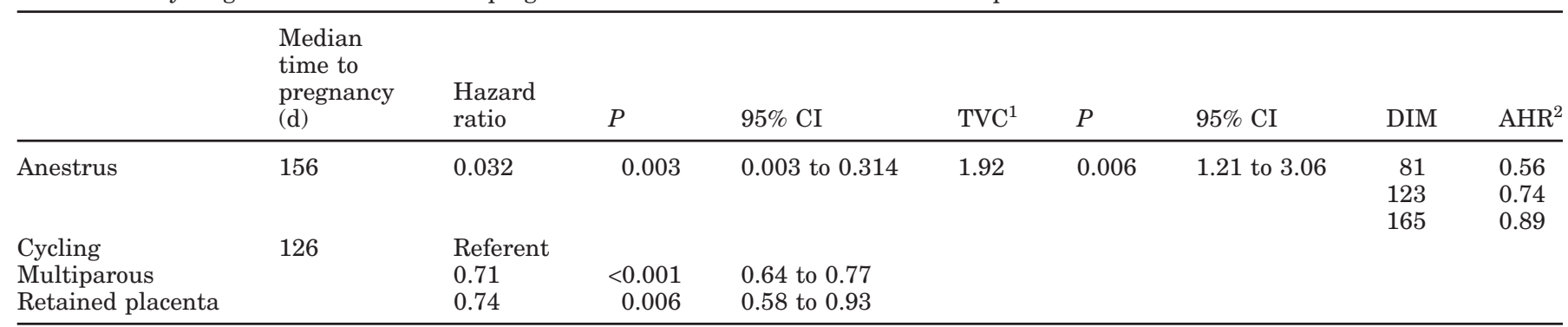

${ }^{1} \mathrm{TVC}=$ Time varying covariate estimate varying with the natural logarithm of time.

${ }^{2} \mathrm{AHR}=$ Adjusted hazard ratio $=$ hazard ratio $\times$ time varying covariate $\mathrm{e}^{\ln (\text { time })}$. 


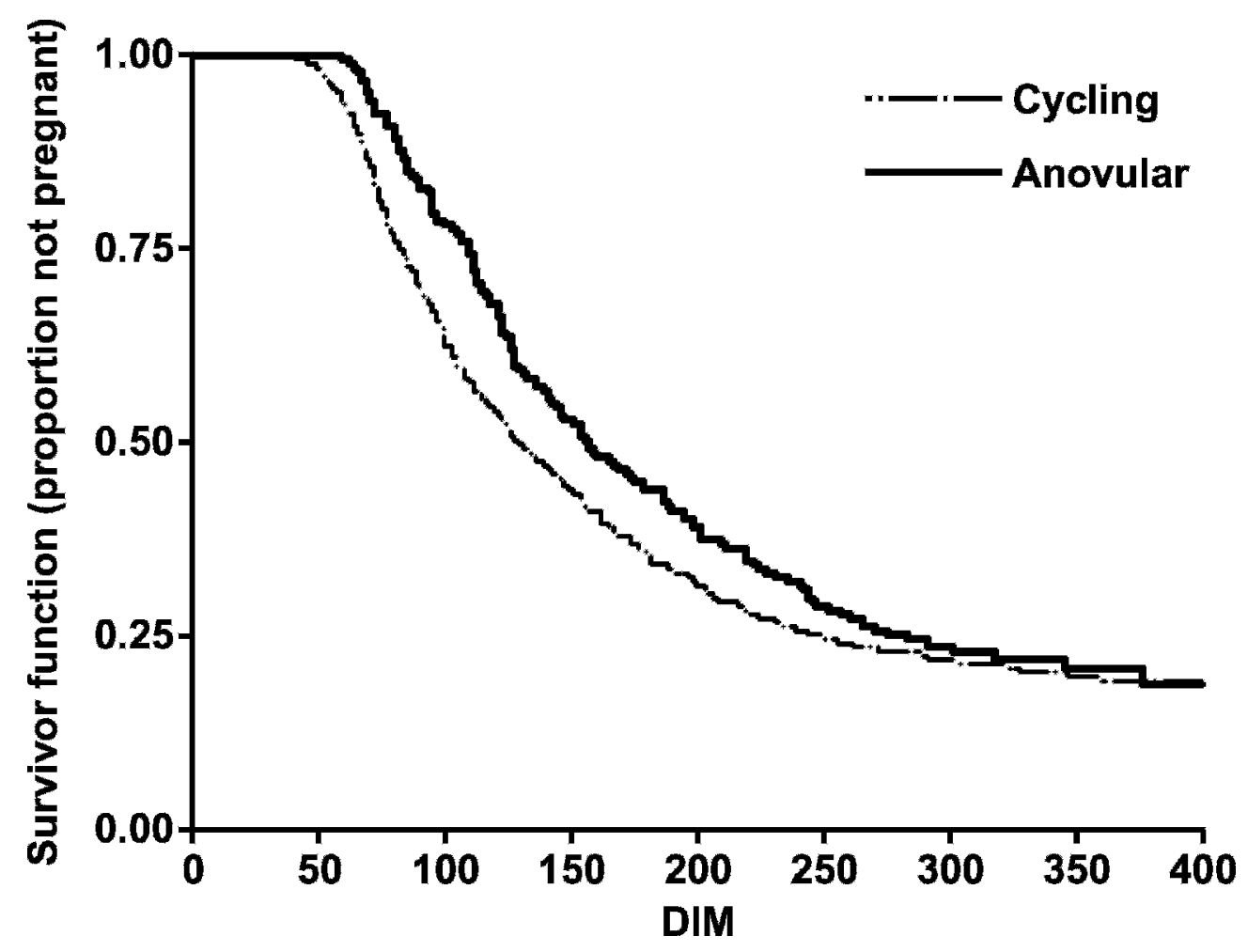

Figure 2. Survival curves of time to pregnancy in 1,341 lactating dairy cows from 18 Ontario dairy herds diagnosed as cycling or anovular based on skim milk progesterone concentrations $>1 \mathrm{ng} / \mathrm{mL}$ determined at 46 and $60 \pm 7 \mathrm{DIM}$.

The prevalences of peripartum diseases and SCK reported were similar to other observational studies in Ontario (McLaren et al., 2005). Dystocia significantly increased the risk of anovulation. This dichotomization of the 4-category calving score (unassisted, easy pull, hard pull, and surgery) is in agreement with other studies in which a composite variable including dystocia, stillbirth, and twin calvings was strongly associated with increased risk of anestrus (Opsomer et al., 2000; Shrestha et al., 2004a).

Peripartum disease events, including retained placenta, displaced abomasum, and lameness, occurring before the end of the voluntary waiting period significantly increased the probability of cows experiencing anovulation. Accounting for the time from calving to disease event, neither clinical ketosis nor mastitis was associated with the risk of failure to cycle. Another study found that after accounting for the impact of season of calving and parity, clinical ketosis increased the risk of anovulation more than 10-fold; however, this association was no longer significant after accounting for other risk factors such as dystocia and abnormal vaginal discharge (Opsomer et al., 2000).

Subclinical ketosis in the first week after calving significantly increased the risk of delayed ovulation. The association between the magnitude of negative energy balance and delayed ovulation is well established (Staples et al., 1990; Butler, 2000). A direct association between increased milk BHBA and delayed onset of luteal activity has not previously been reported; however, Cook et al. (2001) reported decreased probability of pregnancy at first insemination and increased time to pregnancy associated with hyperketonemia. The impact of SCK must be interpreted in light of when ketones were measured. In the present study, SCK in either wk 1 or 2 was associated with anovulation, but when other significant variables were accounted for, only SCK in wk 1 postpartum was associated with anovulation. The mechanism of this is not clear, but the peak incidence of SCK occurs in wk 1 of lactation (Duffield et al., 1998), and cows that are ketotic in wk 1 postpartum may be in more severe maladaptation to negative energy balance that cows that do not experience SCK until wk 2.

Body condition score before calving and at $60 \pm 7$ DIM, and the change between these 2 measurements were not significantly associated with anovulation in this study. Body condition score, and change in BCS had no association with reproductive performance measured by time to first observed estrus, first insemination, and time to pregnancy, although cyclicity was not measured (Ruegg and Milton, 1995). Conversely, a sig- 
nificant association between BCS and BCS loss between calving and first insemination was reported in several studies (Loeffler et al., 1999). The present results do not refute an association between BCS and risk of anovulation as reported by Lopez et al. (2005), but suggests that measurement of circulating BHBA concentrations in early lactation may provide additional information on the risk of anovulatory conditions.

We identified no association between duration of the dry period $(74.1 \mathrm{~d})$ and subsequent return to an ovulatory cycle. Others have suggested that cows with a dry period greater than $77 \mathrm{~d}$ were 2.9 times more likely to suffer prolonged postpartum anovulation than animals dry 64 to $70 \mathrm{~d}$ (Opsomer et al., 2000). The first matureequivalent milk projection was included as a potential risk factor for anestrus because this value is consistently recorded for each animal before the end of the voluntary waiting period. The mean first projection was $9,500 \mathrm{~kg}$. In animals below the mean (5,000 to 9,500 $\mathrm{kg}$ ), the risk of anovulation decreased by $2 \%$ for each $100-\mathrm{kg}$ increase in first projection. A first projection $>9,500 \mathrm{~kg}$ was not associated with a change in risk of anovulation, which is consistent with the results of a smaller study (Lopez et al., 2005). Animals with a low first projection failed to efficiently make the transition into lactation.

Animals calving in the fall were significantly less likely to be anovular relative to animals calving in the winter $(P<0.01)$ or spring $(P=0.05)$. Spring calving was associated with delayed commencement of luteal activity and is not unique to ruminants (Opsomer et al., 2000). The underlying mechanism cannot be determined in the current study; however, there were no differences based on use of pasture in the summer in the milking herd or during the dry period, suggesting that seasonal husbandry differences are not to blame. Furthermore, animals calving in late winter or spring will enter the breeding period during the hot months, which will negatively impact reproductive performance through increased probability of anovulation.

Anestrus was associated with an 8-d increase in the time to first service in herds in which most or all AI was based on detection of estrus. There were 42 anovular cows inseminated based on observed estrus before the second milk sample, suggesting that the estrus was not associated with an ovulation, cows were incorrectly identified as in estrus, or were correctly identified in estrus, but an irregular interovulatory interval followed this heat, consistent with abnormal ovarian activity. As anticipated, time to first AI was not different between cycling and anovular cows in herds using fixed-time insemination programs. Insemination in these herds was not associated with classification of cyclic status.
The probability of pregnancy at first insemination was $30.4,20.3,35.9$, and $29.7 \%$ in cycling and anestrous cows bred at observed estrus, and cycling and anestrous cows bred at TAI, respectively. Animals bred at observed estrus were inseminated earlier than cows inseminated at TAI. The probability of pregnancy increases through the first 80 DIM independent of insemination protocol applied (Stevenson and Phatak, 2005).

The median time to pregnancy increased by $30 \mathrm{~d}$ in anovular cows relative to cycling cows (156 vs. 136 DIM). The impact of anestrus on time to pregnancy violated the proportional hazard assumption of semiparametric survival analysis. To account for this, the impact of anestrus on time to pregnancy was permitted to vary with time. The instantaneous probability of pregnancy in anovulatory cows increased over time such that anovulatory cows returned to a daily probability of pregnancy similar to cycling animals around 165 DIM. The apparent risk of pregnancy loss was low (6\%) and not different between cycling and anovular cows. Moreover, cows were typically diagnosed between 35 and $45 \mathrm{~d}$ after $\mathrm{AI}$ and were not systematically reexamined to measure pregnancy losses; losses were based on reexamination in some herds and pregnancy diagnosis to AI occurring subsequent to a previous pregnancy diagnosis. Therefore, these risks are likely underestimated and are not directly comparable to other studies in which pregnancy was first diagnosed earlier and was systematically followed for at least $28 \mathrm{~d}$ (Santos et al., 2004).

In this small sample of herds, free-stall barns had a lower prevalence of anovulation than did tie-stall barns. Within free-stall facilities, 3- or 6-row barns were more likely to have a higher prevalence of anovulation than 2-row barns. Independent of barn design, at the herd level, the prevalence of anestrus was linearly related to the prevalence of ketosis in the first week. The significance of the ketosis estimate was sensitive to the removal of a leverage herd; however, the direction and magnitude of the coefficient did not change. Given the sample size, this study was unable to identify the characteristics of free-stall barns that decreased the seasonal prevalence of anestrus or any potential interactions. Moreover, the finding that 3-row free-stall barns had a higher prevalence of anovulation than 2-row barns suggests that the potential reduction of linear bunk space per stall, and social dynamics surrounding feeding may account for some of the increase risk in anovulation (DeVries et al., 2004; Mentink and Cook, 2006). Further study of these herd-level effects in a large number of herds is warranted.

\section{CONCLUSIONS}

The prevalence of anovulation (defined as low skim milk progesterone concentration in 2 milk samples 
taken 2 wk apart) before 67 DIM in Ontario was $19 \%$. There was considerable between-herd variation in the prevalence of anestrus, with 2-row free-stall barns having the lowest prevalence of anovulation. Cow-level risk factors included low first mature-equivalent milk projection, SCK in early lactation, displaced abomasum, dystocia, and twinning. The results underline the important associations of peripartum health with reproductive function and performance, and suggest that management in the transition period may reduce the prevalence of anovulation.

\section{ACKNOWLEDGMENTS}

Financial support was provided by the Dairy Farmers of Ontario, the Ontario Ministry of Agriculture and Rural Affairs, the American Association of Bovine Practitioners, and in-kind support from Elanco Animal Health and Schering-Plough Animal Health. The commitment and effort this project received from participating producers and veterinarians are greatly appreciated.

\section{REFERENCES}

Butler, W. R. 2000. Nutritional interactions with reproductive performance in dairy cattle. Anim. Reprod. Sci. 60-61:449-457.

Cook, N. B., W. R. Ward, and H. Dobson. 2001. Concentrations of ketones in milk in early lactation, and reproductive performance of dairy cows. Vet. Rec. 148:769-772.

DeVries, T. J., M. A. von Keyserlingk, and D. M. Weary. 2004. Effect of feeding space on the inter-cow distance, aggression, and feeding behavior of free-stall housed lactating dairy cows. J. Dairy Sci. 87:1432-1438.

Dohoo, I., W. Martin, and H. Stryhn, ed. 2003. Veterinary Epidemiologic Research. AVC Inc., Charlottetown, Prince Edward Island, Canada.

Duffield, T. F., D. Sandals, K. E. Leslie, K. Lissemore, B. W. McBride, J. H. Lumsden, P. Dick, and R. Bagg. 1998. Efficacy of monensin for the prevention of subclinical ketosis in lactating dairy cows. J. Dairy Sci. 81:2866-2873.

Ferguson, J. D., D. T. Galligan, and N. Thomsen. 1994. Principal descriptors of body condition score in Holstein cows. J. Dairy Sci. 77:2695-2703.

Garbarino, E. J., J. A. Hernandez, J. K. Shearer, C. A. Risco, and W. W. Thatcher. 2004. Effect of lameness on ovarian activity in postpartum Holstein cows. J. Dairy Sci. 87:4123-4131.

Geishauser, T., K. Leslie, J. Tenhag, and A. Bashiri. 2000. Evaluation of eight cow-side ketone tests in milk for detection of subclinical ketosis in dairy cows. J. Dairy Sci. 83:296-299.

Gowan, E. W., and R. J. Etches. 1979. A solid-phase radioimmunoassay for progesterone and its application to pregnancy in the cow. Theriogenology 12:327-336.

Gumen, A., J. N. Guenther, and M. C. Wiltbank. 2003. Follicular size and response to Ovsynch versus detection of estrus in anovular and ovular lactating dairy cows. J. Dairy Sci. 86:3184-3194.

Hady, P. J., J. J. Domecq, and J. B. Kaneene. 1994. Frequency and precision of body condition scoring in dairy cattle. J. Dairy Sci. $77: 1543-1547$.
Hernandez, J. A., E. J. Garbarino, J. K. Shearer, C. A. Risco, and W. W. Thatcher. 2005. Comparison of the calving-to-conception interval in dairy cows with different degrees of lameness during the prebreeding postpartum period. J. Am. Vet. Med. Assoc. 227:1284-1291.

Lamming, G. E., and A. O. Darwash. 1998. The use of milk progesterone profiles to characterise components of subfertility in milked dairy cows. Anim. Reprod. Sci. 52:175-190.

Loeffler, S. H., M. J. de Vries, and Y. H. Schukken. 1999. The effects of time of disease occurrence, milk yield, and body condition on fertility of dairy cows. J. Dairy Sci. 82:2589-2604.

Lopez, H., D. Z. Caraviello, L. D. Satter, P. M. Fricke, and M. C. Wiltbank. 2005. Relationship between level of milk production and multiple ovulations in lactating dairy cows. J. Dairy Sci. 88:2783-2793.

McLaren, C. J., K. D. Lissemore, T. F. Duffield, K. E. Leslie, D. F. Kelton, and B. Grexton. 2005. The association of herd milk production and management with a return-over-feed index in Ontario dairy herds. J. Dairy Sci. 88:419-425.

Meadows, C., P. J. Rajala-Schultz, and G. S. Frazer. 2005. A spreadsheet-based model demonstrating the nonuniform economic effects of varying reproductive performance in Ohio dairy herds. J. Dairy Sci. 88:1244-1254.

Mentink, R. L., and N. B. Cook. 2006. Short communication: Feed bunk utilization in dairy cows housed in pens with either two or three rows of free stalls. J. Dairy Sci. 89:134-138.

Moreira, F., C. Orlandi, C. A. Risco, R. Mattos, F. Lopes, and W. W. Thatcher. 2001. Effects of presynchronization and bovine somatotropin on pregnancy rates to a timed artificial insemination protocol in lactating dairy cows. J. Dairy Sci. 84:1646-1659.

Opsomer, G., Y. T. Grohn, J. Hertl, M. Coryn, H. Deluyker, and A. de Kruif. 2000. Risk factors for post partum ovarian dysfunction in high producing dairy cows in Belgium: A field study. Theriogenology 53:841-857.

Ruegg, P. L., and R. L. Milton. 1995. Body condition scores of Holstein cows on Prince Edward Island, Canada: Relationships with yield, reproductive performance, and disease. J. Dairy Sci. 78:552-564.

Santos, J. E., W. W. Thatcher, R. C. Chebel, R. L. Cerri, and K. N. Galvao. 2004. The effect of embryonic death rates in cattle on the efficacy of estrus synchronization programs. Anim. Reprod. Sci. 82-83:513-535.

Shrestha, H. K., T. Nakao, T. Higaki, T. Suzuki, and M. Akita. 2004a. Resumption of postpartum ovarian cyclicity in high-producing Holstein cows. Theriogenology 61:637-649.

Shrestha, H. K., T. Nakao, T. Suzuki, T. Higaki, and M. Akita. 2004b. Effects of abnormal ovarian cycles during pre-service period postpartum on subsequent reproductive performance of high-producing Holstein cows. Theriogenology 61:1559-1571.

Sprecher, D. J., D. E. Hostetler, and J. B. Kaneene. 1997. A lameness scoring system that uses posture and gait to predict dairy cattle reproductive performance. Theriogenology 47:1179-1187.

Staples, C. R., W. W. Thatcher, and J. H. Clark. 1990. Relationship between ovarian activity and energy status during the early postpartum period of high producing dairy cows. J. Dairy Sci. 73:938-947.

STATA Corporation LP. 2005. Stata statistical software: Release 9.1. College Station, TX.

Stevenson, J. S., and A. P. Phatak. 2005. Inseminations at estrus induced by presynchronization before application of synchronized estrus and ovulation. J. Dairy Sci. 88:399-405.

Thatcher, W. W., and C. J. Wilcox. 1973. Postpartum estrus as an indicator of reproductive status in the dairy cow. J. Dairy Sci. $56: 608-610$

Wiltbank, M. C., A. Gumen, and R. Sartori. 2002. Physiological classification of anovulatory conditions in cattle. Theriogenology $57: 21-52$. 